Original Research Article

\title{
Comparison of anti-inflammatory efficacy of lercanidipine and Tanacetum parthenium with indomethacin in rats
}

\author{
Neeraj Rajdan', Atul Jain ${ }^{2 *}$, Alok Dixit ${ }^{1}$, Chandra Veer Singh ${ }^{1}$
}

${ }^{1}$ Department of Pharmacology, Uttar Pradesh University of Medical Sciences, Saifai, Uttar Pradesh, India

${ }^{2}$ Department of Pharmacology, Dr. RML Institute of Medical

Sciences, Lakhnow, Uttar

Pradesh, India

Received: 25 April 2018

Accepted: 04 May 2018

*Correspondence to:

Dr. Atul Jain,

Email: drjainatul1@gmail.com

Copyright: (C) the author(s), publisher and licensee Medip Academy. This is an openaccess article distributed under the terms of the Creative Commons Attribution NonCommercial License, which permits unrestricted noncommercial use, distribution, and reproduction in any medium, provided the original work is properly cited.

\begin{abstract}
Background: Inflammation can be classified as either acute or chronic. NSAIDs are the most commonly prescribed drugs worldwide, and mostly have adverse effects. Lercanidipine a CCB of (DHPs) blocks the mediators of inflammation and has additional anti-inflammatory potential. Tanacetum parthenium (Feverfew) extracts have also shown its anti-inflammatory effects in experimental studies. It was decided to study anti-inflammatory effects of Lercanidipine and Tanacetum parthenium which was compared with Indomethacin. The present study was aimed to evaluate and compare the anti-inflammatory effect of lercanidipine and Tanacetum parthenium with Indomethacin in rats.

Methods: The study was conducted in the department of Pharmacology UPUMS, Saifai after getting approval from IAEC.A total of 24 animals divided into 4 groups of six $(n=6)$ animals each group were used, and the anti-inflammatory effects of both drugs were evaluated by Carrageenan-induced Paw Edema Model by digital Plethysmometer in rats, drug administration was with the same frequency.

Results: The result of the present study had shown that lercanidipine produced anti-inflammatory effect compared to Indomethacin, while its efficacy in reducing paw edema was better at 1 st hour, 48 and 72 hours while at 2 nd hour and $3^{\text {rd }}$ hour Indomethacin had better efficacy. Tanacetum parthenium also decreased paw edema at $2^{\text {nd }}, 3^{\text {rd }}, 48$ and 72 hour while at $1^{\text {st }}$ hour no effect was seen. However, at 72 hours, shown good efficacy compared to lercanidipine and Indomethacin.

Conclusions: Lercanidipine could be a promising anti-inflammatory drug in reducing the inflammation and edema. However, herbal drug (Tanacetum parthenium) has shown anti- inflammatory efficacy when compared with Indomethacin. Both drugs were found safe during our study.
\end{abstract}

Keywords: Carrageenan, Inflammation, Lercanidipine, Tanacetum parthenium, Plethysmometer

\section{INTRODUCTION}

Inflammation is a reaction of vascularised connective tissue to local injury. Inflammation is a fundamentally protective response, the ultimate goal of which is to get rid of both initial cause of cell injury and the consequences of such injury. Without inflammation infections would go unchecked, wounds would never heal and injured organs would become permanent festering sores. ${ }^{1}$
Inflammation can also be evoked by a wide variety of noxious agents (e.g., infections, drugs, physical injuries). The ability to mount an inflammatory response is essential for survival in environmental pathogens and injury; in some situations and diseases, the inflammatory response may be exaggerated and sustained without apparent benefit and even with severe adverse consequences. ${ }^{2}$ 
Inflammation is normally a protective mechanism, but when inflammation persist for longer duration along with pain leads to pathology then it needs to be treated.

The development of NSAIDs, with reduced potential to cause gastric ulcers, was released and demonstrated that clinically useful NSAIDs inhibits the cyclooxygenase enzymes, which were also present in the gastric mucosa. ${ }^{3}$

The finding that cyclo-oxygenase present in inflammatory lesions (COX2) was distinct from that found in the stomach (COX1) led to the development of selective COX2 inhibitors, such as celecoxib. These drugs provide relief from many of the symptoms of arthritis and have a reduced potential to cause gastric ulceration. ${ }^{4}$

The drugs available for the treatment of inflammation are:

1. Non- steroidal anti-inflammatory drugs (Selective, Non selective, Preferential COX)

2. Drugs modifying anti- rheumatic drugs

3. Corticosteriods

Drugs opted for the studies were:

\section{Lercanidipine hydrochloride}

Lercanidipine is an L-type calcium channel blocker of the dihydropyridine class, that block the entry of calcium into the muscle cells of the heart and the blood vessels. Calcium ions increase the lipoxygenase products by activating 5lipoxygenase enzyme and eicosanoids synthesis by activating cytosolic phospholipase- $\mathrm{A}_{2}$. So inhibiting these calcium ions proves to be a potential target for antiinflammatory drugs. ${ }^{5}$

Currently CCBs enjoy the status of first line antihypertensive drugs used singly or in combination, their antihypertensive efficacy is comparable to that of $\beta$ blockers. The choice of CCBs in combination therapy is influenced by coexisting disease such as angina, asthma, diabetes and peripheral vascular disease (PVD). These drugs possess some distinct advantages relative to other vasodilator. ${ }^{6}$

\section{Tanacetum parthenium}

Feverfew appears to be an inhibitor of prostaglandin synthesis. Its active constituent sesquiterpene lactones, inhibit production of inflammatory prostaglandins in rat and human leukocytes. Inhibition was irreversible. Feverfew extracts were found to inhibit mitogen-induced tritiated thymidine uptake by human peripheral blood mononuclear cells, interleukin-2-induced tritiated thymidine uptake by lymphoblasts, and prostaglandin release by interleukin-1-stimulated synovial cells. Parthenolide blocks stritiated thymidine uptake by mitogen-induced human peripheral blood mononuclear cells. ${ }^{7}$
The leaves of this plant are eaten or used as infusions in conditions like arthritis, migraine and asthma. It has also being claimed to be useful for treating conditions like tinnitus/vertigo, fever, menstrual disorders, difficulty in labour, stomach-ache, toothache and insect bites. ${ }^{8,9}$

\section{Indomethacin}

Indomethacin, a methylated indole is indicated for the treatment of moderate to severe rheumatoid arthritis, osteoarthritis, and acute gouty arthritis; ankylosing spondylitis. $^{10}$

Objectives of the study was:

- To evaluate anti-inflammatory effect of Lercanidipine and Tanacetum parthenium using Carrageenan induced paw edema model

- To compare anti-inflammatory effects of Lercanidipine and Tanacetum parthenium with Indomethacin using Carrageenan induced paw edema

- To find out adverse effects if any, during the study.

\section{METHODS}

The present study was conducted on adult rats (150-250g) of either sex in the Department of Pharmacology in UPUMS, Saifai. Healthy Wistar albino rats aged around 34 months weighing $150-250 \mathrm{gm}$ was obtained from the animal house, UPUMS Saifai, Etawah (U.P), after getting approval by Institutional Animal Ethical Committee (IAEC).Animals were acclimatized to the laboratory conditions for 7 days prior to the study and maintained on normal diet and ad libitum water.

\section{Method of collection of data (including sampling procedure)}

A total of 24 animals will be divided into 4 groups of six $(n=6)$ animals each group, was subjected to the following tests.

\section{Study design}

The anti-inflammatory effects of Lercanidipine and Tanacetum parthenium were evaluated by Carrageenaninduced Paw Edema Model by digital Plethysmometer after giving the drugs in rats. Routes of drug administration were i.p. - For Lercanidipine and Tanacetum Parthenium

\section{Inclusion criteria}

- Wistar rat of either sex weighing 150-250gm.

- $\quad$ Aged 3-4 months.

- Healthy with normal behaviour activity.

\section{Exclusion criteria}

- Wistar rat $<150$ g or $>250$ g and aged $<3$ months or $>4$ months. 
- $\quad$ Pregnant female rat or those who have delivered.

- Animals previously used in other experiments

1. Group -I (Control) received normal saline in dose of $0.1 \mathrm{ml} / \mathrm{kg}$ b.w. i.p once a day for carrageenan-induced paw edema model.

2. Group -II (Indomethacin) received Indomethacin in dose of $10 \mathrm{mg} / \mathrm{kg}$ b.w. i.p. once a day for carrageenan-induced paw edema model.

3. Group- III (Lercanidipine) group received Lercanidipine in dose of $900 \mu \mathrm{g} / \mathrm{kg}$ b.w. i.p. once a day for carrageenan-induced paw edema model.

4. Group -IV (Tanacetum parthenium) group received Tanacetum parthenium $20 \mathrm{mg} / \mathrm{kg}$ b.w. i.p. once a day for carrageenan-induced paw edema model.

\section{Digital plethysmometer}

\section{Principal of operation}

The measuring cell consists of two vertical interconnected Perspex tube, the larger of which is used to measure displacement. The water level in the smaller tube, which contains the transducer, follows that of the large one and is proportional to the volume dipped in the large tube. A sophisticated electronic circuit, monitored by the compensation electrodes, correct the level electrodes "reading" thus generating a signal proportional to the level only and hence to the dipped volume

Test used for assessing anti- inflammatory effects.

\section{Carrageenan-induced Paw Edema Model}

Paw edema was induced in the hind right paw of rats by injecting $0.1 \mathrm{ml}$ of freshly prepared $1 \%$ solution of carrageenan. The left paw served as control Paw volume up to the ankle joint was measured in drug treated and untreated groups before and $3 \mathrm{~h}$ after carrageenan injection using digital plethysmometer to record the paw volume at $15,30,60,90,120,150,180$ and 210 min after carrageenan challenge. Percent change in paw volume was calculated and expressed as the amount of inflammation. ${ }^{11}$
The data was compared by using statistical tests such as student's t test and ANOVA test followed by post hoc test. Results was expressed as mean \pm SD. $p$ value was calculated, referring to the appropriate drug. Value of $\mathrm{p}<0.05$ was considered as statistically significant.

\section{Statistical analysis}

1. Student's -t test was used to evaluate significance of the drugs, within the individual groups.

2. Different groups were compared by using ANOVA test. $^{12}$

All the drugs and reagents were procured from Sigma Aldrich Pharmaceuticals Pvt. Ltd. for studying antiinflammatory effect.

\section{RESULTS}

At $1^{\text {st }}$ hour lercanidipine and Indomethacin had shown anti-inflammatory effects as evidenced by decrease paw edema with maximum efficacy of lercanidipine compared to Indomethacin (Table 2). Tanacetum parthenium has not shown any anti-inflammatory effect.

However between lercanidipine and tanacetum parthenium, lercanidipine was superior as compared to Tanacetum parthenium and has decreased paw edema significantly.

At $2^{\text {nd }}$ hour all the three drugs (Lercanidipine, Tanacetum parthenium and Indomethacin) had shown antiinflammatory effect with maximum efficacy of Indomethacin compared to other two test drugs which was statistically significant (Table 3).

However, between lercanidipine and tanacetum parthenium, lercanidipine has decreased paw edema which was statistically significant.

At $3^{\text {rd }}$ hour all the three drugs (Lercanidipine, Tanacetum parthenium and Indomethacin) had shown antiinflammatory effect with maximum efficacy of Indomethacin compared to other two test drugs which was statistically significant (Table 4). However, between lercanidipine and tanacetum parthenium, lercanidipine has decreased paw edema which was statistically significant.

Table 1: Mean paw volume changes in different groups from day 1 at $\left(1^{\text {st }}, 2^{\text {nd }}, 3^{\text {rd }}\right.$ hr $)$ to 72 hours in Carragenan Induced Paw Edema Model.

\begin{tabular}{|lllllll|}
\hline & $\mathbf{0 ~ h r s}$ & $\mathbf{1}^{\text {st }} \mathbf{h r}$ & $\mathbf{2}^{\text {nd }} \mathbf{h r}$ & $\mathbf{3}^{\text {rd }} \mathbf{h r}$ & $\mathbf{4 8} \mathbf{h r}$ & $\mathbf{7 2 h r}$ \\
& $\mathbf{R t}$ & $\mathbf{R t}$ & $\mathbf{R t}$ & $\mathbf{R t}$ & $\mathbf{R t}$ & $\mathbf{R t}$ \\
\hline Control & $1.29 \pm 0.07$ & $1.34 \pm 0.16$ & $1.44 \pm 0.14$ & $1.49 \pm 0.05$ & $1.42 \pm 0.10$ & $1.4 \pm 0.09$ \\
\hline Standard (Indomethacin) & $1.20 \pm 0.07$ & $1.32 \pm 0.01$ & $1.24 \pm 0.03$ & $1.22 \pm 0.03$ & $1.22 \pm 0.06$ & $1.14 \pm 0.08$ \\
\hline Test I (Lercanidipine) & $1.2 \pm 0.05$ & $1.27 \pm 0.01$ & $1.28 \pm 0.03$ & $1.26 \pm 0.03$ & $1.21 \pm 0.04$ & $1.03 \pm 0.06$ \\
\hline Test II (Tanacetum Parthenium) & $1.28 \pm 0.1$ & $1.43 \pm 0.01$ & $1.38 \pm 0.11$ & $1.39 \pm 0.04$ & $1.31 \pm 0.04$ & $.95 \pm 0.05$ \\
\hline P value & 0.325 & $<0.01$ & $<0.01$ & 0.01 & 0.0026 & 0.20 \\
\hline
\end{tabular}


Table 2: Mean paw volume after administration of lercanidipine, tanacetum parthenium and indomethacin at $\mathbf{1}^{\text {st }}$ hour.

\begin{tabular}{|c|c|c|c|c|}
\hline $\begin{array}{l}\text { S. } \\
\text { No }\end{array}$ & & Mean & SD & $\mathbf{P}$ value \\
\hline \multirow[b]{2}{*}{1} & Control & 1.34 & 0.16 & \multirow{2}{*}{$\begin{array}{l}\mathrm{p} \text { value } \\
<0.01\end{array}$} \\
\hline & Indomethacin & 1.32 & 0.01 & \\
\hline \multirow{2}{*}{2} & Control & 1.34 & 0.16 & \multirow{2}{*}{$\begin{array}{l}\mathrm{p} \\
\text { value }<0.01\end{array}$} \\
\hline & Lercanidipine & 1.27 & 0.01 & \\
\hline \multirow[b]{2}{*}{3} & Control & 1.34 & 0.16 & \multirow[b]{2}{*}{$\begin{array}{l}\mathrm{p} \text { value } \\
<0.01\end{array}$} \\
\hline & $\begin{array}{l}\text { Tanacetum } \\
\text { Parthenium }\end{array}$ & 1.43 & 0.01 & \\
\hline \multirow{2}{*}{4} & Standard & 1.32 & 0.01 & \multirow{2}{*}{$\begin{array}{l}\mathrm{p} \text { value } \\
0.91\end{array}$} \\
\hline & Lercanidipine & 1.27 & 0.01 & \\
\hline \multirow[b]{2}{*}{5} & Standard & 1.32 & 0.01 & \multirow{2}{*}{$\begin{array}{l}\mathrm{p} \text { value } \\
0.91\end{array}$} \\
\hline & $\begin{array}{l}\text { Tanacetum } \\
\text { Parthenium }\end{array}$ & 1.43 & 0.01 & \\
\hline \multirow[b]{2}{*}{6} & Lercanidipine & 1.27 & 0.01 & \multirow[b]{2}{*}{$\begin{array}{l}\mathrm{p} \text { value } \\
0.91\end{array}$} \\
\hline & $\begin{array}{l}\text { Tanacetum } \\
\text { Parthenium }\end{array}$ & 1.43 & 0.01 & \\
\hline
\end{tabular}

Table 3: Mean paw volume after administration of lercanidipine, tanacetum parthenium and indomethacin at $2^{\text {nd }}$ hour.

\begin{tabular}{|c|c|c|c|}
\hline & Mean & SD & P value \\
\hline Control & 1.44 & 0.14 & \multirow{2}{*}{$<0.01$} \\
\hline Indomethacin & 1.24 & 0.03 & \\
\hline Control & 1.44 & 0.14 & \multirow{2}{*}{$<0.01$} \\
\hline lercanidipine & 1.28 & 0.03 & \\
\hline Control & 1.44 & 0.14 & \multirow{2}{*}{0.40} \\
\hline Tanacetum Parthenium & 1.38 & 0.11 & \\
\hline Indomethacin & 1.24 & 0.03 & \multirow{2}{*}{0.91} \\
\hline lercanidipine & 1.28 & 0.03 & \\
\hline Indomethacin & 1.24 & 0.03 & \multirow{2}{*}{0.004} \\
\hline Tanacetum Parthenium & 1.38 & 0.11 & \\
\hline lercanidipine & 1.28 & 0.03 & \multirow{2}{*}{0.004} \\
\hline Tanacetum Parthenium & 1.38 & 0.11 & \\
\hline
\end{tabular}

Table 4: Mean paw volume after administration of lercanidipine, tanacetum parthenium and indomethacin at $3^{\text {rd }}$ hour.

\begin{tabular}{|c|c|c|c|}
\hline & Mean & SD & P value \\
\hline Control & 1.49 & 0.05 & \multirow{2}{*}{0.09} \\
\hline Indomethacin & 1.22 & 0.03 & \\
\hline Control & 1.49 & 0.05 & \multirow{2}{*}{0.09} \\
\hline lercanidipine & 1.26 & 0.03 & \\
\hline Control & 1.49 & 0.05 & \multirow{2}{*}{0.43} \\
\hline Tanacetum Parthenium & 1.39 & 0.04 & \\
\hline Indomethacin & 1.22 & 0.03 & \multirow{2}{*}{0.91} \\
\hline lercanidipine & 1.26 & 0.03 & \\
\hline Indomethacin & 1.22 & 0.03 & \multirow{2}{*}{0.49} \\
\hline Tanacetum Parthenium & 1.39 & 0.04 & \\
\hline lercanidipine & 1.26 & 0.03 & 0.49 \\
\hline
\end{tabular}

At 48 hour maximum anti-inflammatory effect was shown by lercanidipine followed by Tanacetum parthenium and Indomethacin which was statistically significant (Table 5). However, between lercanidipine and tanacetum parthenium, lercanidipine was superior as compared to tanacetum parthenium, and has decreased paw edema significantly.

Table 5: Mean paw volume after administration of lercanidipine, tanacetum parthenium and indomethacin at 48 hour.

\begin{tabular}{|c|c|c|c|}
\hline & Mean & SD & $P$ value \\
\hline Control & 1.42 & 0.1 & \multirow{2}{*}{0.09} \\
\hline Indomethacin & 1.22 & 0.06 & \\
\hline Control & 1.42 & 0.1 & \multirow{2}{*}{$<0.01$} \\
\hline lercanidipine & 1.21 & 0.01 & \\
\hline Control & 1.42 & 0.1 & \multirow{2}{*}{0.001} \\
\hline Tanacetum Parthenium & 1.31 & 0.04 & \\
\hline Indomethacin & 1.22 & 0.06 & \multirow{2}{*}{$<0.01$} \\
\hline lercanidipine & 1.21 & 0.01 & \\
\hline Indomethacin & 1.22 & 0.06 & \multirow{2}{*}{0.17} \\
\hline Tanacetum Parthenium & 1.31 & 0.04 & \\
\hline lercanidipine & 1.21 & 0.01 & \multirow{2}{*}{0.001} \\
\hline Tanacetum Parthenium & 1.31 & 0.04 & \\
\hline
\end{tabular}

Table 6: Mean paw volume after administration of lercanidipine, tanacetum parthenium and indomethacin at 72 hour.

\begin{tabular}{|c|c|c|c|}
\hline & Mean & SD & P value \\
\hline Control & 1.4 & 0.09 & \multirow{2}{*}{0.64} \\
\hline Indomethacin & 1.14 & 0.08 & \\
\hline Control & 1.4 & 0.09 & \multirow{2}{*}{0.17} \\
\hline lercanidipine & 1.03 & 0.06 & \\
\hline Control & 1.4 & 0.09 & \multirow{2}{*}{0.05} \\
\hline Tanacetum Parthenium & 0.95 & 0.05 & \\
\hline Indomethacin & 1.14 & 0.08 & \multirow{2}{*}{0.32} \\
\hline lercanidipine & 1.03 & 0.06 & \\
\hline Indomethacin & 1.14 & 0.08 & \multirow{2}{*}{0.11} \\
\hline Tanacetum Parthenium & 0.95 & 0.05 & \\
\hline lercanidipine & 1.03 & 0.06 & \multirow{2}{*}{0.51} \\
\hline Tanacetum Parthenium & 0.95 & 0.05 & \\
\hline
\end{tabular}

At $72^{\mathrm{hr}}$ surprisingly maximum efficacy was shown by Tanacetum parthenium followed by lercanidipine and Indomethacin (Table 6). However, lercanidipine and Tanacetum parthenium have shown similar effect which was not significant.

The findings of the present study are summarised in the following statements:

At $1^{\text {st }}$ hour lercanidipine and Indomethacin had shown anti-inflammatory effects as evidenced by decrease paw edema with maximum efficacy of lercanidipine compared to Indomethacin. Tanacetum parthenium has not shown any anti-inflammatory effect. However between 
lercanidipine and tanacetum parthenium, lercanidipine was superior as compared to tanacetum parthenium and has decreased paw edema significantly.

At $2^{\text {nd }}$ all the three drugs (Lercanidipine, Tanacetum parthenium and Indomethacin) had shown antiinflammatory effect with maximum efficacy of Indomethacin compared to other two test drugs which was statistically significant. However, between lercanidipine and tanacetum parthenium, lercanidipine has decreased paw edema which was statistically significant.

At $3^{\text {rd }}$ hour all the three drugs (Lercanidipine, Tanacetum parthenium and Indomethacin) had shown antiinflammatory effect with maximum efficacy of Indomethacin compared to other two test drugs which was statistically significant. However, between lercanidipine and tanacetum parthenium, lercanidipine has decreased paw edema which was statistically significant.

At 48 hour maximum anti-inflammatory effect was shown by lercanidipine followed by Tanacetum parthenium and Indomethacin which was statistically significant. However between lercanidipine and tanacetum parthenium, lercanidipine was superior as compared to tanacetum parthenium, and has decreased paw edema significantly.

At $72 \mathrm{hr}$ surprisingly maximum efficacy was shown by Tanacetum parthenium followed by lercanidipine and Indomethacin. However, lercanidipine and tanacetum parthenium have shown similar effect which was not significant.

\section{DISCUSSION}

Inflammation is characterized by increased blood flow and vascular permeability along with accumulation of fluid, leukocytes and inflammatory mediators. It is also characterized by the development of specific humoral and cellular immune responses to pathogens which are present at the site of tissue injury.

Inflammation is a common symptom of many diseases including autoimmune diseases like rheumatoid arthritis, SLE, gout, bronchial asthma, osteoarthritis, tenosynovitis, fracture, uveitis, erythema nodosum which are a challenge in medicine to control such type of manifestations, presently lots of NSAIDs available but none of them is ideal in controlling these symptoms and sometimes lifelong treatment is required .Medical fraternity needs an ideal drug for treatment which can be safe and cheaper and controls symptoms of patient.

As per literature search is concerned we found that lercanidipine which act through different mechanism (Ltype channel) and a strong anti-inflammatory drug.

Khaksari M et al, performed a study on calcium channel blockers (verapamil and nifidepine) to evaluate their mechanism of action on inflammation in rat paw edema model. ${ }^{13}$ This study indicated that these CCBs block Ltype calcium channel and exert a potent anti-inflammatory action in rat paw. The study was conducted using carrageenan-induced rat paw edema model, two different doses of nifidepine and verapamil $(25 \mu \mathrm{g} / \mathrm{kg}$ and $400 \mu \mathrm{g} / \mathrm{kg}$ i.p.) were used. Edema was assessed by calculating the paw volume changes.

Authors use Tanacetum parthenium because it is a herbal drug which is quite safe compared to available NSAIDs. So present study designed for its anti-inflammatory evaluation and we used Carragenan edema model. Authors have not come across in literature regarding their study till now and safety is an important issue for any drug to be used.

Present study was designed to evaluate the antiinflammatory effect of lercanidipine a CCB of DHP class. The present study also evaluated the anti-inflammatory effect of Tanacetum parthenium which also had been studied by many scientists. Other main objective of present study was to evaluate anti-inflammatory effect of concomitant use of lercanidipine and Tanacetum parthenium in rats. As per literature search till date, effects of concomitant use of lercanidipine and Tanacetum parthenium were never been studied.

Previous studies were different compared to present study because of limitations of number of groups used in their study and we have taken more groups of animals. They have used large doses and we have used different doses of the drugs administered in the study.

\section{CONCLUSION}

The result of the present study had shown that lercanidipine produced anti-inflammatory effect in carrageenan induced paw edema model and its effect was comparable to standard drug Indomethacin while its efficacy in reducing paw edema was better at $1^{\text {st }}$ hour, 48 and 72 hours while at $2^{\text {nd }}$ hour and $3^{\text {rd }}$ hour Indomethacin has better efficacy. These findings were statistically significant.

Tanacetum parthenium had shown mild anti-inflammatory effect compared to Indomethacin and lercanidipine as it has decreased paw edema at $2^{\text {nd }}, 3^{\text {rd }}, 48$ and 72 hour while at $1^{\text {st }}$ hour Tanacetum parthenium has not shown any effect and has shown good efficacy at 72 hours, compared to lercanidipine and Indomethacin, this probably may be due to different mechanism of action and its onset may be slow while duration of action may be longer.

This study showed that in carrageenan edema model lercanidipine had shown good anti-inflammatory efficacy which is comparable to Indomethacin, while Tanacetum parthenium had shown mild anti-inflammatory compared to Indomethacin and lercanidipine probably due to delayed onset of action. 
No adverse effects were observed during the entire course of study. Further studies including clinical use of these drugs are needed to substantiate the above mention findings of the present study.

Funding: No funding sources

Conflict of interest: None declared

Ethical approval: The study was approved by the Institutional Animal Ethical Committee UPUMS, Saifai Etawah, India

\section{REFERENCES}

1. Robbins and Cotran. Acute and Chronic Inflammation. In: Rebecca Gruliow, (ed). Pathologic Basis of Disease, $9^{\text {th }}$ Ed. Philadelphia: Elsevier publication; 2015:69.

2. FitzGerald. Anti inflammatory, anti pyretic and analgesic agent. In: Brunton LB, Lazo JS, Parker KL, eds. Goodman and Gilman's. The pharmacological basis of therapeutics. $12^{\text {th }}$ Ed. United States: Mc Graw Hill publication; 2011:959-960.

3. Vane JR. Inhibition of prostaglandin synthesis as a mechanism of action for aspirin like drugs. Nat New Biol. 1971;231:232-5.

4. Hawkey CJ, Jackson L, Harper SE, Simon TJ, Mortensen E, Lines CR. Review article: the gastrointestinal safety profile of rofecoxib, a highly selective inhibitor of cyclooxygenase- 2 in humans. Aliment Pharmacol Ther. 2001;15:1-9.

5. Vasigar P, Batmanabane M. Anti-inflammatory activity of calcium channel blocker lercanidipine hydrochloride. J Pharmacol Pharmacother. 2013;4(4):238-42.

6. Sharma HL, Sharma KK. Drug therapy for hypertension Principles of Pharmacology. $3^{\text {rd }}$ Ed. Paras Publication; 2017:274-275.
7. Neill LA, Barrett ML, Lewis GP. Extracts of feverfew inhibit mitogen-induced human peripheral blood mononuclear cell proliferation and cytokine mediated responses: A cytotoxic effect. Br J Clin Pharmacol. 1987;23:81-3.

8. Berry MI. Feverfew faces the future. Pharm J. 1984;232:611-4.

9. Murphy H, Mitchell JR, Heptinstall S. Randomized double-blind placebo controlled trial of feverfew in migraine prevention. Lancet. 1988;2(8604):189-92.

10. Gerald F. Anti-inflammatory, anti-pyretic and analgesic agent. In: Brunton LB, Lazo JS, Parker KL, eds. Goodman and Gilman's. The pharmacological basis of therapeutics, $12^{\text {th }}$ Ed.United States: Mc Graw Hill publication; 2011:984.

11. Kulkarni SK, Mehta AK, Kunchandy J. Antiinflammatory actions of clonidine, guanfacine and BHT 920 against various inflammagen-induced acute paw edema in rats. Archives Internationales de Pharmacody- namicet de Therapie. 1968;279(2):32434.

12. Mahajan BK. Method in biostatistics. $6^{\text {th }}$ Ed. New Delhi Jaypee publication; 2006:15.

13. Khaksari M, Mahani SE, Mahmoodi M. Calcium channel blockers reduce inflammatory edema in the Calcium channel blockers reduce inflammatory edema in the rat: Involvement of the hypothalamus-pituitaryadrenal axis rat: Involvement of the hypothalamuspituitary-adrenal axis. Indian J Pharmacol. 2004;36(6):351-4.

Cite this article as: Rajdan NR, Jain A, Dixit A, Singh CV. Comparison of anti-inflammatory efficacy of lercanidipine and Tanacetum parthenium with indomethacin in rats. Int J Basic Clin Pharmacol 2018;7:1072-7. 